\title{
Correction to: Performance analysis of an unreliable $M / G / 1$ retrial queue with two-way communication
}

\author{
Muthukrishnan Senthil Kumar ${ }^{1} \cdot$ Aresh Dadlani $^{2}$ (D) Kiseon $\mathrm{Kim}^{3}$
}

Received: 26 December 2017 / Revised: 15 June 2018 / Accepted: 25 July 2018 /

Published online: 4 October 2018

(c) Springer-Verlag GmbH Germany, part of Springer Nature 2018

\section{Correction to: Operational Research https://doi.org/10.1007/s12351-018-0417-y}

In the original publication, the funding information has been published incorrectly. The correct funding information should read

"This research was a part of the project titled "Development of an automated fishcounter system and measurement of underwater farming-fish", funded by the Ministry of Oceans and Fisheries, Korea."

The original article can be found online at https://doi.org/10.1007/s12351-018-0417-y.

Aresh Dadlani

aresh.dadlani@nu.edu.kz

Muthukrishnan Senthil Kumar

ms_kumar_in@yahoo.com

Kiseon Kim

kskim@gist.ac.kr

1 Department of Applied Mathematics and Computational Sciences, PSG College of Technology,

Coimbatore 641-004, India

2 Department of Electrical and Computer Engineering, School of Engineering, Nazarbayev University, Astana, Kazakhstan 010000

3 School of Electrical Engineering and Computer Science, Gwangju Institute of Science and Technology, Gwangju 61005, South Korea 